\title{
A lost decade for third-wave democracies?
}

\author{
Yun-han Chu, Kai-Ping Huang, Marta Lagos, and Robert Mattes
}

Yun-han Chu is Distinguished Research Fellow at the Institute of Political Science at Academia Sinica, a professor of political science at National Taiwan University, and director of the Asian Barometer Survey. Kai-Ping Huang is assistant professor of political science at National Taiwan University and the corresponding author of this article (kaipinghuang@,ntu.edu.tw). Marta Lagos is the founding director of Latinobarómetro Corporation. Robert Mattes is professor of politics at the University of Strathclyde and a founding member of Afrobarometer.

Amid what is now recognized as a years-long democratic recession that includes not only backslidings in younger democracies but dysfunctions in established ones, it is important to see the phenomenon not only through the lenses of experts at Freedom House or V-Dem, but from the standpoint of ordinary citizens. It is they, after all, who should have the final say over what kind of democratic political system they are experiencing and whether its quality of governance lives up to their expectations.

Support for and satisfaction with democracy may come from many sources including the provision of political goods, economic success, protection of human safety, and improvement in governance (in terms of transparency, fairness, impartiality, and the like). Such tangible benefits deeply affect citizens' commitment to democracy. ${ }^{1}$ Experts make their assessments of how democracy is doing in this country and ordinary citizens make theirs. What citizens experience may accord with what the experts see, or it may not. By offering a citizen-based perspective, we are not dismissing the experts, but we do hope to enrich the overall picture of the current state of democracy around the world.

Using the longitudinal data accrued from the Global Barometer Surveys (GBS), ${ }^{2}$ we can track changes in popular orientation toward democracy in 51 countries across three continents 
over the past decade of democratic decline [Number updated after excluding South Asia.YHC_KPH]. Our data show significant backsliding in the attitudinal underpinnings of democracy between 2006-08 and 2016-18, buttressing the early expert warnings of global democratic recession. Declining support for democracy is closely related to diminishing satisfaction with how democracy works in practice. In some countries, disappointment with poor governance has led people to put more trust in the executive than in the legislature, in hopes that a strong leader can solve all ills. The risks of such a course are clear: Focusing power in the executive tends to erode checks and balances and may even pave the way to electoral autocracy. A strong leader (often a populist) sold as a savior can undermine institutions and the underlying principle of popular sovereignty in pursuit of immediate goals. Such potent leaders tend, moreover, to heighten political polarization and this has a cost since the polarization itself makes democracy less appealing.

Our empirical analysis suggests that solving the structural and institutional problems responsible for poor governance and eroded mechanisms of popular accountability is the only way to make up democracy's lost decade.

\section{Expert versus Popular Assessments}

How do experts' assessments of democracy compare to popular evaluations over the last decade? In order to answer this question, we compare the aggregate data on popular support for democracy that we have been able to gather from $\mathrm{GBS}^{3}$ with the annual Freedom House index. The data available for East Asia were gathered across the period 2006-16, while for sub-Saharan 
Africa and Latin America the period was 2005-18. ${ }^{4}$ [Cut South Asia b/c data is old.-LJD ;

\section{Done $\mathrm{YHC}$ KPH]}

At the most general level, New York-based Freedom House divides the world into three parts: Countries are Free, Partly Free, or Not Free. One can gauge the magnitude of global democratic recession by calculating the percentage of net changes in terms of democratic backsliding from one point in time to a later point. Looking at how widespread popular support for democracy is in each given society (because such support is so important to democratic consolidation) we create our own threefold classification. Our gauge is a standardized question which asks respondents if they agree that "democracy is always preferable to any other kind of government." Based on answers to this question, countries can be classed as "robust," "weak," or "fragile" democracies. Following Larry Diamond, we call any country where more than twothirds of respondents explicitly agree that democracy is always better a "robust" democracy (at least insofar as its foundation in popular sentiment goes). Countries where this figure is between 50 and 66 percent we call "weak," and any country where it falls below 50 percent we call a "fragile" democracy. ${ }^{6}$

We know there are pitfalls here. The question's use of the "D-word" might inflate the level of support for democracy, for instance, given that many respondents may feel it "socially unacceptable" to deny the value of democracy itself. Then too, in some authoritarian countries the observed level of support for democracy can seem higher than it really is because the regime calls itself a democracy (usually with at least one adjective attached) and many respondents who seem to be avowing their endorsement of democracy will in fact merely be echoing that party line. ${ }^{7}$ Even when these pitfalls are present, however, comparing changes over time on these measures can be revealing. 
First we examine changes in the two parallel assessments over the same period. For the same 51 countries that GBS surveyed periodically between 2005 and 2018, "Free" countries dropped from 24 to 19 while "Partly Free" countries increased from 23 to 27 . By contrast, the changes in popular support for democracy were more dramatic, as "robust" countries dropped from 30 to 21 [The figures are updated, excluding South Asia.-YHC_KPH].

Across the three regime types, Not Free countries on average registered the highest level of support in 2005, followed by Free countries. A decade later, the average level of democracy support dropped for each class. In Free countries, the mean support level fell from 67 to 61 percent, while in the Partly Free set it went from 65 to 62 percent and in Not Free countries from 80 to 70 percent. [Please fill in the percentages.-LJD] [The percentages are updated, excluding South Asia._-YHC_KPH] Within the decade, five countries (Dominican Republic, Indonesia, Lesotho, Mali, and Mexico) fell from Free to Partly Free, yet removing them from the set of Free countries leaves democracy support within that class little changed.

Variation within the set of Free countries widened over the decade, indicating that in some countries opinions about democracy have become more sharply split. Within Free countries, one might identify a growing population of disgruntled citizens who no longer think that democracy is always superior to any alternative regime type. When more citizens in Free countries think this way (as they have been doing in El Salvador, Brazil, South Africa), one can anticipate that fewer people would stand up against violations of democratic principles by authoritarian-inclined politicians, and that more people would fall in line behind populist leaders. On the other hand, the strong support for democracy that we found in a few Partly Free countries (such as Burkina Faso and Venezuela — the latter of which has since become Not Free) means that in these countries the ideal of democracy still has a reservoir of support behind it, which 
suggests potential for democratic advance. Nevertheless, compared to a decade ago, democracy has lost appeal across the board, especially among people living in Free countries.

Data accrued by regular opinion polls such as GBS and the Freedom House's scores on which the three-part classification is based stem from two different approaches to assessing the state of democracy in a given country. The former is basically bottom-up replying on what ordinary citizens have been experiencing at the grassroots while the latter is essentially top-down counting on the qualitative judgement by the experts who typically places emphasis on major events of system-wide or long-term significance. It often takes a big change (such as the 2012 military coup that knocked Mali from Free down to Partly Free status) to cause the experts at Freedom House to shift a country from one class to another-though it is possible for a country at the low end of one category to fall into the category below due to no more than a small change. [I am really uncomfortable with making too much of changes in these big FH categories. A country at the low end of Free can fall down into Partly Free due to a small change. Other countries may fall farther but remain in the Free category.---LJD Note qualifying language that I added after the long dash.-PJC; We have tried to tone down the contrast between the two $\left.-\mathrm{YHC} \_\mathrm{KPH}\right]$

Therefore, regular opinion polls are more sensitive to what is happening on the ground and for that reason they can pick up undercurrents before their cumulative effects help trigger ostensible political events. This probably explains why scholars examining the changes in all Freedom House scores between 1972 and 2012 concluded that the trend of democratic recession was marginal since it mainly occurred in Latin America and sub-Saharan Africa, regions where backsliding democracies already tended to be frail even before they began actually regressing toward authoritarianism. ${ }^{8}$ 
Another expert survey, V-Dem (short for Varieties of Democracy, www.v-dem.net), traced the changes across 2006-16 and concluded that there existed challenges to democracy but no evidence showing that "democracy is caught in a global crisis." "These observations lagged behind our survey data, which reveal that support for democracy was already in decline across the board during the same period. In Latin America, Latinobarómetro found a gradual decline in support for democracy that had begun by 2008. Not until 2018, after the rise of rightist populism in the West and the conspicuous ascendance of China and Russia as authoritarian "role models", did the two expert surveys recognize global democratic retreat as a reality.

Looking at data points over time, we can see that popular discontent had been brewing for a decade in democracies and has eroded popular support for the democratic regime in most countries.

\section{Specific and Diffuse Support, 2005-18}

The GBS collects data on both support for and satisfaction with democracy. Satisfaction manifests itself through popular approval of how the given country's democratic system is performing. Respondents are asked, "How satisfied are you with the way democracy is working in [our country]?" In theory, support for democracy should be more stable than satisfaction, which can rise or fall due to government performance. Another way of putting it is that while satisfaction is a governance question, support is a regime question. Nevertheless, scholars increasingly believe that the legitimacy of any given democratic regime is affected eventually by

the outputs it produces. ${ }^{10}$ In other words, while the short-term performance of a government does not affect citizens' support for democracy as an ideal regime type, repeated failures to deliver 
both political and economic goods will sooner or later start costing democracy some of its support.

The last decade has made it clear that the growing problems of elites abusing power and violating democratic principles in third-wave democracies have exacerbated the decline in satisfaction with democracy expressed by ordinary people. This declining satisfaction has in turn eaten away at popular support for democracy and weakened the pro-democratic popular sentiments that should act as a barrier to democratic backsliding.

Francis Fukuyama has pointed out that the root cause of rising popular discontent is the poor performance of third-wave democracies that lack state capacity to maintain rule of law, accountability, and the delivery of basic public goods. ${ }^{11}$ Corruption, government inefficiency and abuses of power plague almost all new democracies, especially in lower-income countries. At the same time, globalization and the 2008 global financial crisis hit many third-wave democracies hard as world trade stagnated and commodity prices plunged amid monetary policies that staved off instability but at the price of worsening inequality.

Figure 1 shows the relationship between satisfaction with the way democracy works and support for democracy across regions over multiple waves of Barometer surveys. We note three key findings. First, across all regions - sub-Saharan Africa, Latin America, and East Asia - we detected a downward trend in satisfaction with democracy (as shown by the data points moving to the left along the horizontal axis). Latin America, which is surveyed annually, registered the most glaring drop in satisfaction, especially since 2010. In 2018, the average share of respondents across the region who said that they were satisfied with how democracy was working in their respective countries only reached 25 percent. In Africa, the magnitude of growing dissatisfaction is significant as well. East Asian countries have maintained fairly high 
levels of democratic satisfaction with only a mild setback between 2010 and 2016. The region's average is pushed up, however, by the much higher levels of satisfaction with "democracy" expressed by respondents in nondemocracies such as China and Singapore. There, the regimes call themselves democracies but attach adjectives to qualify them as something distinct from classic liberal democracies. [Is this still a current practice by these regimes-to label themselves "democracies" but of a special sort? Larry thinks maybe not. Cut if no longer relevant.-PJC; As of today, the leaders in China, Vietnam and Singapore still exercise “democracy" discourse and narrative --- YHC_HKP] If we focus on just the Free countries in East Asia, the satisfaction level is modest, averaged at 61\% across Japan, Korea, Mongolia and Taiwan in 2016, compared to $72 \%$ in hybrid regimes and nondemocracies. [Give the average for these E.A. Free countries from the latest survey.—LJD; The 2019 data from Japan and South Korea are still being cleaned ---YHC_KPH]

Second, the relationship between support for democracy as a regime and satisfaction with how democracy performs is complex. Our data reveal substantial variation across regions. In Africa, ordinary people have maintained their relatively high support for democracy despite decreasing levels of satisfaction with democracy. In Latin America, and to some extent in East Asia as well, support for democracy and satisfaction with democracy are tightly linked. Once again, Latin America registered the sharpest decline in support for democracy. There, the trend followed the economic cycle: The drop in support for democracy does not begin until 2010, which is when governments began running out of funds to counter the negative impacts of the 2008 financial crisis.

Third, in most countries satisfaction with democracy has registered consistently below support for democracy (indicated by all the data points that are above the diagonal line in Figure 
1). East Asia, where citizens' support for democracy consistently trails satisfaction (indicated by all the data points below the diagonal line), presents a perplexing anomaly to this generalization. The source of this anomaly is two-fold: [It's not perplexing if you separate out the autocracies in East Asia from the democracies.—LJD; Our data show that Support trailing behind Satisfaction in Taiwan and Mongolia consistently and three out of four waves in South Korea ---YHC_KPH] First, it is due to a strong presence of high-performing hybrid and one-party regimes in the region, which pushed up popular satisfaction with regime performance without necessarily lifting the support for democracy. Next, it is due to the fact that a large number of citizens in East Asian young democracies - in particular Taiwan, South Korea and Mongolia -tend to apply an unusually high benchmark in judging democratic system while a bulk of the baby-boom generations still harboring lingering nostalgia with the country's authoritarian past. In our 2016 survey, $25 \%, 28 \%$ and $37 \%$ of our respondents respectively in South Korea, Taiwan and Mongolia, instead of agreeing with that "Democracy is always more preferable to any other kind of government," embraced the view that "Under some circumstances, an authoritarian government can be preferable to a democratic one". [Talk of a "perplexing anomaly" is misleading because there are two very different patterns: One for the authoritarian countries such as China and another for the democracies. It would be better to disaggregate East Asian countries into those two groups, then rewrite this passage to reflect that way of sort out the data. Or in other words, please compute two sets of averages for East Asia, one for democracies, one for nondemocracies, and then you have established this point without the need for a "probably."-PJC; Based on our empirical analysis, separating the democracies and non-democracies makes no difference with regard to the above generalization. --YHC_KPHJ 


\section{FIGURE 1 HERE}

Regional averages, of course, have the drawback of concealing important nuances that can observed at the level of individual countries. In Figure 2, therefore, we get more "granular" by ranking countries according to their Freedom House status (Free, Partly Free, or Not Free) as of 2005, with arrows to display the changes in support and satisfaction (see Figure 2). The arrow represents data in the later time and two vertical dashed lines refer to 66 percent and 50 percent, the two thresholds that differentiate the countries with robust support for democracy from those where such support is weak.

In East Asia, support for democracy increased in five of thirteen cases, but in only one case (Japan) did support for democracy surpass the consolidation threshold of 66 percent. Japan also registered a significant increase in satisfaction with democracy during this period thanks to the tenacity of Abe government in revamping Japan's economy after suffering two "lost decades". /Cambodia has no democracy to consolidate. Let's not list it here.-LJD; OK--$\boldsymbol{Y H C - K P H ] ~ B o t h ~ s a t i s f a c t i o n ~ w i t h ~ a n d ~ s u p p o r t ~ f o r ~ d e m o c r a c y ~ d e c l i n e d ~ i n ~ m o s t ~ E a s t ~ A s i a n ~}$ countries. In the cases of Indonesia, the Philippines, Singapore, and Taiwan, curiously, increased satisfaction with democracy did not feed into greater support for it. Indonesia is the only one of our East Asian cases that Freedom House downgraded a category, shifting the country's status from Free to Partly Free because of a restrictive NGO law adopted in 2013. (Indonesia was already near the margin so this single change was enough to make Freedom House shift the country's categorization.) Support for democracy remained high in Indonesia throughout the period covered by this study. 
In Latin America, the trend was similar. Fourteen of eighteen countries saw a fall in democracy support from 2005 to 2018. All ten Free countries, except Peru, [How many were there?-PJC; Ten] manifested different degrees of declining support with El Salvador registering the sharpest drop from $70 \%$ to $30 \%$. By 2018, six of the ten Free countries in the region have fallen under the "weak" category with Costa Rico being the only Free country that has stayed above our "robust" threshold. [high? High but declining?—LJD ] Across Latin America, the aftermath of the economic crisis (2010 and later) saw countries exhaust their capacity to undertake countercyclical fiscal policies to try to soften the impact of the crisis. Protest and ungovernability that has occurred with dissatisfaction with the performance of democracy has finally taken a toll on democracy itself. The region's average level of satisfaction has dropped from $46 \%$ to $25 \%$ between 2010 and 2018 . This negative gravitation has dragged down the region's average level of support for democracy by a magnitude of $14 \%$. While growing disenchantment with democracy did not to give noticeable rise to support for authoritarianism ought right, it did lower the barrier for the return of non-democratic option as more Latino respondents embraced the view that "For people like me, it does not matter whether we have a democratic or a nondemocratic regime." [This point seems disconnected from the survey data. Demonstrate the impact of these actions on public support for and satisfaction with democracy, or drop this passage.—LJDJ.

In sub-Saharan Africa, support for democracy rose over the decade in eleven of twenty countries—five [five?] Free and five [four?] Partly Free. On average across the region, support for democracy held steady, but this was because rising democracy support in some countries canceled out declines in others. [NB: We have cut South Asia completely from the article. The 
data are just too old. Seven years is past useful shelf life. India alone has had two national elections since 2013, etc.—LJD/PJC; OK---YHC_KPH]

Taking all 51 countries listed in Figure 2, we can say that in Latin America and subSaharan Africa, changes in democracy support and changes in satisfaction with democracy are strongly correlated with one another (and that strong correlation becomes even more discernable when we do the bivariate analysis at the individual level), while in East Asia there is only a weak correlation. For Free countries in particular, declining satisfaction with democracy is driving down support for democracy in most countries, such as Brazil, Chile, Uruguay, Benin, Cape Verde and South Africa. [the democracies of?--LJD] There are a few exceptions showing distinctive local dynamics. In the case of Mongolia and Peru, where support for democracy had already reached its bottom (below the 50\% watermark) before the subsequent drop in satisfaction with democracy. In Namibia and Senegal, the floor of support for democracy has been resilient enough to withstand the decline in satisfaction. [the democracies of?-PJC]

Thus, when we turn to analyzing matters country by country, regime performance turns out to be very important in explaining the changes in democracy support observed in most countries. In fact, the explanatory power of perceived regime performance-how satisfied people say they are with "the way democracy works in their country" [OK? Are we talking about democratic regimes here or all regimes? Need to make that clear.-PJC] [To avoid confusion, we use the original wording in the survey-YHC_KPH] — is stronger in sub-Saharan Africa than it is in Latin America, and far stronger than the effect of regime performance on democracy support that we observe in East Asia.

This confirms our argument that support for democracy is closely tied to satisfaction with democracy. Flagging regime performance-failure to deliver consistently the materialist and 
political "goods" that citizens expect their government to produce — is the driver behind the erosion of popular support for democracy observed in recent years. This is true in all three regions under consideration, and is also an indicator of the low level of democratic consolidation that leaves many third-wave democracies vulnerable to backsliding.

\section{FIGURE 2 HERE}

\section{Hope for a Better Future or Abandon Democracy}

By calculating the differences between support and satisfaction in 2005 and 2018, respectively, we can see whether the gaps between support and satisfaction have widened or narrowed in different countries. Overall, citizens in electoral authoritarian regimes (as opposed to single-party regimes such as the ones in China and Vietnam) tend to voice a level of support for democracy that exceeds their level of satisfaction with how "democracy" (which may, let us recall, not be very democratic) is working in their country. This pattern holds for Cambodia and Hong Kong in East Asia, Venezuela in Latin America, and Mali, Mozambique, and Uganda in sub-Saharan Africa.

In Latin America, support for democracy eroded over the decade from a regional average of 66 percent in 2010 to 52 percent in 2018. Across the quarter-century of the Latinobarómetro, respondents in Argentina, Costa Rica, and Uruguay have shown the highest levels of support for democracy. Satisfaction with democracy has been volatile in Argentina and Costa Rica due to economic crises and corruption scandals, but not so much in Uruguay. In Bolivia and Ecuador, new constitutions boosted both support for and satisfaction with democracy early in the Morales 
and Correa administrations. In each country, however, those increases vanished when the president engaged in manipulations aimed at allowing him to retain power. (Ecuador also suffered an economic crisis in 2019, two years after Correa left the presidency, when it was forced to comply with harsh IMF conditions.) In both countries, elites have been the driving force of crisis - Morales ultimately had to leave because of a police rebellion —so it is safe to assume that in each place, democracy's prospects for consolidation depend heavily on how the government performs. Democracy is unlikely to prevail when government fails.

The gap between support and satisfaction has narrowed in many sub-Saharan Africa's Partly Free countries. In Nigeria, Zambia and Malawi, we saw a concurrent upward movement of both support and satisfaction and a narrowing of the gap between the two thanks to a much larger increase in people's satisfaction with regime performance. For the incumbent regime this is an encouraging trend in terms of regime stability. At the same times, however, it might also imply that many hybrid regimes and electoral authoritarian regimes are here to stay and the prospect of further democratization is not that great. [Delete the following paragraph on Zimbabwe --YHC_KPH] Turning to one of sub-Saharan Africa's most stubborn authoritarian cases, we observe that more political space opened in Zimbabwe following the 2013 adoption of a new constitution. In November 2017, long-ruling president Robert Mugabe at last stepped down at the age of 93, but this was due to infighting within the ruling party. While Zimbabweans' satisfaction [?? - eds.] with democracy more than doubled between 2005 and 2018, going from 19 to 42 percent, while support for democracy [Do you mean "support for"??-eds.] descended by almost 10 points from its peak of 91 percent. [The original could not have been right. I assumed it was inverted, so what really happened is that satisfaction with democracy increased from 19 to 42 percent, while support increased to 91 percent. In fact, I just checked the 
numbers on Afrobarometer online. Support for democracy (always preferable) went from went from 66 percent in 2005 to 75 percent in 2018. So it wasn't a drop. Satisfaction went from 14 pct in 2005 to 38 pct in 2018, adding “very" and "Fairly" satisfied. None of this aligns exactly with what you reported here. Are you tossing out "don't know" answers to reach these higher percentages? If so, you need to explain that here. PLEASE check the data-LJD][We checked the original datasets and confirmed the numbers are correct. The discrepancies are due to how we handled "Don't knows"; we treat them as missing values and exclude those cases in calculation. We reported this statistical practice in Endnote 6. There are large numbers of don't knows in the democracy support question in the 2005 Afrobarometer survey in many countries. For instance, there are 262 don't knows in Madagascar, 288 in Mozambique, 767 in Tanzania, and 286 in Zimbabwe. --- YHC_KPH]

The observed trend among East Asia's Partly Free countries is worrisome. In Singapore, the Philippines, Malaysia and Thailand, the satisfaction with regime performance remained high (or improved substantially) but support for democracy has significantly declined. This might reinforce the incumbent's resolve to constrain the political space while concentrating their effort on delivering materialist output. [Delete the following paragraph as it is vague and speculative] Among ordinary people living under regimes that increasingly constrain political space, ["Restricted" is a vague term. Please clarify. Do you mean only electoral authoritarian regimes? I am guessing not all authoritarian regimes.—LJD] aspirations for democracy run high. This provides grounds for optimism about the future of democracy - it remains the regime for which people long when they live under the heels of rulers who rob them of their rights and freedoms. Finally, the concurrent downward movement observed in many Free Countries is most worrisome. It undermines the democratic resiliency, i.e., that when democratic institutions do not 
live up to expectations, citizens may turn their backs on democracy. This is a danger to democratic regimes that cannot fix chronic problems, such as corruption, racial discrimination, a widening income gap, and government inefficiency. Although these countries may retain the democratic rankings that experts assign them, there is a risk that fed-up citizens could embrace a leader who promises to fix all ills even if it means sacrificing democratic institutions.

\section{Executives, Legislatures, and Trust}

As citizens begin to feel powerless to extract effective policy responses from the government, populist leaders may come to the fore with vows to "fix things." Once elected, these leaders are likely to find institutions of accountability an inconvenience. Emboldened by a majority electoral mandate, executives gather more power into their own hands, maintaining an electoral façade but hollowing out checks and balances. ${ }^{12}$ At first, these leaders bring reforms, and citizens' trust in the executive goes up. Focused on results (there are promises to the voters that must be kept), the chief executive may attack the legislature as inefficient and corrupt - $a$ roadblock standing in the way of reform. Citizens' trust in this institution of representation goes down. In polling, therefore, a widening gap between the trust that citizens are willing to place in the executive and the trust that they accord to the legislature may be the harbinger of executive aggrandizement.

In order to see whether there is a trend among citizens to trust one branch more than the other, we calculate the gaps between trust in the executive and trust in the legislature for the 2005-18 period. There are two main findings. First, when people start trusting the executive branch more than the legislature, the country as a whole is likely to display a higher level of 
democratic satisfaction but a lower level of support for democracy, resulting in a larger gap between the two attitudes. In the Philippines, trust in the president rose from $40 \%$ to $55 \%$. At the same time, trust in the legislature continued to hover around $40 \%$. Support for democracy, however, lagged behind satisfaction in 2014 (47\% vs. 59\%) compared to 2006 ( $55 \%$ vs. 38\%), indicating that more trust in the president boosts satisfaction but not support for democracy. Compared to Arroyo, Aquino's presidency was more reliable in the eyes of citizens despite inadequate responses to natural disasters and ongoing corruption. As democracy unable to dismantle political dynasties seeking personal interests through the Congress and other public offices, the Filipinos increasingly pin their hopes on leaders. Actually, in the latest survey done in 2018, trust in the (Duterte's) presidency rose to $89 \%$ and satisfaction with democracy soared to $70 \%$, while support for democracy further plummeted to $40 \%$. Duterte is seen a populist, authoritarian-oriented leader who engaged in extrajudicial killing in his war on drugs, but his popularity baffled his opponents. This is the paradox of executive aggrandizement. [Here, you should discuss an example (or two) of the main phenomenon, so please add a case here. Bangladesh, the outlier case, is excised because as noted we feel the South Asia data is just too old to be part of the analysis presented in this essay. Data for Bangladesh ends as of 2013, but in 2014 the opposition boycotted the election and there was a transition to what is now a more blatantly authoritarian regime.—LJD/ While we generally consider executive aggrandizement a harbinger to eroding democracy, ordinary people might see it as a necessary measure for realizing "democracy."[We need more cases here (cases from the countries under survey, of course) to establish the general validity of this observation about everyday citizens and their view of executive aggrandizement. - LJD/ In other words, an aggrandizing executive may look 
to many like a savior when democracy is equated with inefficiency and chaos. [This seems a reasonable generalization, but again, an example would help-LJD]

The second is that when people trust the legislative more than the executive branch, support for democracy tends to be on the upswing. The Venezuelan case displays this. Conflicts between the executive and the legislature escalated after 2015, when the opposition won an overwhelming victory in that year's legislative elections. President Nicolás Maduro’s response was to gather more power and to supplant the National Assembly. He did this with a progovernment body, the National Constituent Assembly, chosen by means of a July 2017 special election (convened by a Maduro decree) that more than forty countries rejected. While Venezuela's Freedom House rating fell from Partly Free to Not Free between 2005 and 2018, the continuing high support for democracy $(79 \%)$ in the presence of low democratic satisfaction (12\%) [Give figures. - L LDD] means that Venezuelans' yarning desire for democracy as an ideal regime type remained resilient. [This is unclear. If confidence in democracy means support for democracy, it is true by definition. If confidence means trust, then we need to distinguish support for democracy as a general principle from the way the system behaves in its actual operations.--LJD Might it be better to say that the Venezuelan public's aspiration to see democracy come to Venezuela remains robust?-PJC][We think support for democracy means different things in different contexts. In democracies, it is the confidence in the democratic systems. In non-democracies, democracy represents an ideal regime type. In the case of Venezuela, we think it is aspiration to see the current regime be replaced by a democratic one, not confidence in the current regime. $-\mathrm{YHC} \mathrm{KPH]}$

Venezuela shows that extreme executive aggrandizement is still vulnerable to backfire, and Putinism may last a long while but is not intrinsically irreversible. [This may be true, but it's 
a hard to generalize on the basis of a single case. Putin, for example is still popular, and the incumbent in Zimbabwe got enough support to be able to claim he won the presidential election. - LJD] While it may require more rigorous causal analysis, our preliminary analysis suggests that when the popular trust in legislature is at least not trailing too far behind that of the executive, movement in the two key indicators -- support for democracy and satisfaction with the way democracy works -- is more likely to yield a virtuous cycle. This more balanced popular foundation, in turn, helps promote regime stability. By default, this virtuous cycle is more likely to emerge under parliamentary than under either semi-presidential or presidential system since the latter is more liable to the syndrome of divided government. Lopsided trust in the executive, conversely, may suggest that citizens' longing for a political "savior" to pull the country out of its predicament is becoming strong enough to open a door that an aggrandizing executive will be tempted to walk through. [How can we be sure what is the cause and what the effect here? Do aggrandizing executives and polarization cause diverging views among social groups, or could it be the other way round? Readers will wonder how you prove causation._-PJC] [Do we know from the data that this is happening, that different social groups have different attitudes toward democracy? Can you give two or three examples?-LJD] [We have done some analyses but dropped that part from our previous version because there are many ways that we can disaggregate the constituencies. So here we present this just as a preliminary conclusion.-YHC_KPH]

\section{Support for Democracy: Reservoir Dogged?}


Is democracy backed up by a reservoir of people who doggedly support it no matter what? Our analysis shows a two-sided picture. On one side, people who live in Not Free or Partly Free countries tend to support democracy at high rates: They do not have it, and they want it. On the other side, citizens of Free countries often reveal to Barometer pollsters falling support for democracy. The common cause on both sides is declining satisfaction with government performance. In democratic countries, poor performance erodes support for democracy as a regime. In Not Free countries, poor government performance has the opposite effect: It seems to sustain and even increase commitment to democracy as a regime to be hoped for.

The relationship between shifts in democratic satisfaction and shifts in support for democracy is important. When both democracy support and democratic satisfaction go up, we have a virtuous cycle: Satisfaction with government performance bolsters support for democracy as a regime. [We cut "best scenario" claim b/c surely the best ideal scenario is when democratic governments perform well so satisfaction is high and so is support for democracy. - LJDJ When satisfaction lags support, this implies that there are dissatisfied democrats who demand better-performing democratic governance. That means in turn that ordinary people still cherish democracy as the ideal regime type.

If both satisfaction and support drop into significant decline, you get a vicious cycle in which poor government performance robs democracy of its appeal. Finally, when satisfaction with democracy is higher than support for it, democracy (if it exists) is standing on shaky ground: The government's performance is winning public approval but failing to build support for democracy as a regime that people prefer over all others on grounds firmer than "things seem to be going well at the moment." 
Most of the Free countries in this study have entered a vicious cycle, albeit from different starting points. In particular, Cape Verde, El Salvador, South Africa, and Uruguay have experienced two-digit declines in support and satisfaction with democracy. That said, Uruguay still boasts a higher level of popular support for democracy than any other Latin American country. Among the Free countries being surveyed Mongolia is the only country where the observed level of satisfaction has gone down but the support for democracy has gained some strength albeit from a rather low base. The observed increment by 5 percentage points [Do you mean percentage points?-PJCl, however, is not enough to elevate this struggling democracy from the "fragile" to "weak" category. Democracy's popular foundation in Mongolia is still much shakier than the country's consecutive "Free" rating might imply. Mongolians have been disappointed by poor governance since the country adopted multiparty elections in 1990 . Although elections are generally free and fair, two patronage-wielding parties dominate the political scene, and rampant corruption has stalled democracy's progress. The current government and set of political arrangements meet most democratic criteria, but people are alienated from the two main parties and long for a "real democracy" that responds to their needs.

Among the Partly Free countries and territories, Hong Kong offers the most dramatic case of increasing democracy support. It went up by ten percentage points [OK??-PJC] [OK.$\boldsymbol{K P H}$ ] while satisfaction with regime performance plunged by 12 percentage points. [Give precise figure. - LJDJ Recall that our figures stop at 2018 - the current level of dissatisfaction with the lack of democratic reform that people in Hong Kong feel dates from before the massive protests of 2019. [The discussion of HK's 2019 events should stop with this comment since the protests postdate the latest survey and therefore cannot explain the survey results. $-L J D \&$ PJCJ By contrast, democratic support and satisfaction both went down by more than ten points 
[OK??—PJC] [OK- $\boldsymbol{Y H C}$ KPH] in the Dominican Republic and Mozambique. The Dominican Republic faces not only a crisis involving immigration from Haiti, but also a political one caused by President Leonel Fernández's desire for a third consecutive term (which would be his fourth term overall).

Among Not Free countries, Cambodia under dictator Hun Sen stands out /along with Zimbabwe?--LJD][Zimbabwe shows declining democracy support amid increasing satisfaction. Thus, it is not comparable with Cambodia when satisfaction declines and support increases. $-\boldsymbol{Y H C} \boldsymbol{K P H}$ ] for the high level of democracy support expressed by its citizenry; support for democracy has increased from $61 \%$ to $74 \%$ while satisfaction with democracy dropped from $80 \%$ to $69 \%$ between 2006 and 2014. [Give the figures here for Cambodia and Zimbabwe ad any other high-scoring Not Free countries. And what is the gap with democratic satisfaction?--LJD] In China, by contrast, support for democracy declined from $81 \%$ to $55 \%$ between 2008 and 2016, while satisfaction with the way "democracy" was working in the country declined from $88 \%$ to $72 \%$ over the same period. [Exact years and numbers needed. Please fill them in.-LJD] Although democracy entails different meanings there, government performance falling short of promises also lowered support for that regime. To what extent some unforeseen calamities such as the novel coronavirus outbreak of late 2019 and early 2020 might intensify this effect deserves further scrutiny. [Authors: Do you want to add a few lines here about how the Communist party-state's lack of transparency and urge to suppress bad news seem to have made matters worse, especially in the crucial early days after acute cases began appearing?-eds.]

Taken together, the GBS findings reviewed here show that, no matter what definitions people attach to democracy, most ordinary citizens among our surveyed countries still view it as 
an "ideal" regime that is worthy of their support. Yet in Free countries, chronic problems of public corruption and unresponsive authorities have driven down support for democracy and created a vacuum that populist leaders may exploit to undermine democratic institutions. In countries that are not so free, there is a reservoir of support for democracy, but this only appears when people realize that abandoning freedom does not guarantee better governance in return.

The next decade promises a continued struggle between the demands of peoples for more democracy and the ambitions of elites to hang onto power. Governmental performance is the key thing to watch, since there seems to be a threshold of "bad" below which it starts to drag down support for democracy as a regime. As structural and institutional factors continue to diminish state capacity in many countries, democracy is likely facing another lackluster decade.

Are we observing the waning of the third-wave democracies? Have the third-wave democracies experienced a lost decade? From the perspective of ordinary people, there have been visible and significant setbacks. Although expert surveys were sunnier and concluded that the retreat of the third-wave democratization between 2005 and 2016 was worrying but not threatening, results based on popular surveys showed a precipitous fall in support for democracy across countries during the same period, with much stronger reasons for pessimism.

Democratic aspirations still run high in East Asia and sub-Saharan Africa despite increasing dissatisfaction with how democratic governments work in practice. Latin America is its own story. Democratic satisfaction and support ran strong during the boom years from 2002 to 2008, only to fall as economic crisis gripped one country after another. But in Latin America, at least, the third wave is over: The region is no longer fully democratic.

In countries veering toward or mired in authoritarianism, levels of support for democracy as a regime often run high. The support represents a lament as well as an aspiration. The greatest 
risk to existing democracy is to be found in countries where citizens trust the executive far more than they trust the legislature. This imbalance tends to lower citizens' support for democracy while increasing their satisfaction with its perceived performance: They feel that their elected (typically populist) chief executive is going to set things right at last. The polarization that typically accompanies populism's rise afflicts not only less free countries, but stable liberal democracies as well.

Unlike expert surveys, surveys of everyday people provide an evaluation based on all major aspects of social, political, and economic life in a given society. This is an indispensable source of information that can detect ground-level dynamics before the watershed events to which experts react.

\section{NOTES}

${ }^{1}$ For examples of the large literature on this point, see Juan Linz and Alfred C. Stepan, "Toward Consolidated Democracies," Journal of Democracy 7 (April 1996): 14-33; and Yun-han Chu et al., "Public Opinion and Democratic Legitimacy," Journal of Democracy 19 (April 2008): 74-87.

\section{The Global Barometer Surveys (www.globalbarometer.net) incorporate data on public opinions and attitudes from Afrobarometer, Arab Barometer, Asian Barometer, Eurasia Barometer, and Latinobarómetro.}

\section{${ }^{3}$ Arab Barometer and Eurasia Barometer proceed on unique schedules that required us to omit them from this longitudinal study.}


4 In Africa most surveys were conducted in 2005 with the exception of Burkina Faso and Liberia, where only 2008 surveys are available. [So do you actually have longitudinal data from Africa, or just a bunch of surveys taken in mostly the same year?-ed.] [Afrobarometer conducted five rounds of surveys between 2005 and 2018, and only 18 countries are overlapped in the 2005 and 2018 surveys. To include more countries in the analysis, we include Burkina Faso and Liberia, which were first surveyed in 2008. YHC_KPH]

${ }^{5}$ Respondents are also given two other options: That "under some circumstances, an authoritarian government can be preferable to a democratic one," or that "for people like me, it does not matter whether we have a democratic or a nondemocratic regime". [To be complete and exactly accurate---YHC_KPH]

6 Support for democracy reaching 66 percent is a hallmark of democratic consolidation. See Larry Diamond, Developing Democracy: Toward Consolidation (Baltimore: Johns Hopkins University Press, 1999), 68-69. In calculating the level of support for democracy in a given country we included all respondents who picked one of the three substantive options while treating those answering "Don't Know" as missing cases. This means in most countries between $8 \%$ and $15 \%$ of the respondents are excluded from our analysis.

7 Ronald Inglehart, "How Solid Is Mass Support for Democracy and How Can We Measure It?" Political Science and Politics 36 (January 2003): 51-57; Yun-han Chu and 
Min-hua Huang, "The Meanings of Democracy: Solving an Asian Puzzle," Journal of Democracy 21 (October 2010): 114-22.

8 Jørgen Møller and Svend-Erik Skaaning, "The Third Wave: Inside the Numbers," Journal of Democracy 24 (October 2013): 97-109.

9 Valeriya Mechkova, Anna Lührmann, and Staffan I. Lindberg, "How Much Democratic Backsliding?" Journal of Democracy 28 (October 2017): 168.

10 Juan J. Linz, "Crisis, Breakdown and Re-equilibration," in Juan J. Linz and Alfred Stepan, eds., The Breakdown of Democratic Regimes (Baltimore: Johns Hopkins University Press, 1978): 3-24.

${ }^{11}$ Francis Fukuyama, "Why Is Democracy Performing so Poorly?” Journal of Democracy 26 (January 2015): 11-20.

12 Nancy Bermeo, "On Democratic Backsliding," Journal of Democracy 27 (January 2016): 5-19. 